\title{
Figurações do feminino na escritura de Marguerite Duras
}

\author{
Yara dos Santos Augusto Silva \\ Mestre em Letras: Estudos Literários / UFMG
}

\begin{abstract}
RESUMO
Conforme a análise que desejamos apresentar, em A doença da morte (1982) e O amante (1984), o modo de escritura concebido por Marguerite Duras (1914-1996) joga com as possibilidades de significar o feminino por meio da construção dos personagens, da estruturação narrativa, bem como pelos recursos formais de linguagem empregados.
\end{abstract}

PALAVRAS-CHAVE

Escritura, feminino, erotismo, literatura francesa

Lacan me deixava atordoada. E aquela sua frase: "Ela não deve saber que escreve, nem aquilo que escreve. Porque ela se perderia. E isso seria uma catástrofe.” Esta frase tornou-se, para mim, uma espécie de identidade de princípio, um "direito de dizer” totalmente ignorado pelas mulheres.

Marguerite Duras. ${ }^{1}$

A educação formal e a palavra escrita foram, por um longo tempo, privilégios estritamente masculinos. Em razão disso, é possível afirmar que, submetidas à autoridade patriarcal e à administração do lar, as mulheres e suas investidas no campo da criação literária alcançaram pouca expressividade até o final do século 19. Embora desde sempre tenha existido um feminino operante, grande parte da produção de diários, poemas e romances redigidos por essas mulheres se perdeu ou foi ignorada pela historiografia literária. Dentre alguns dos nomes que se destacaram no período, temos escritoras como Emily Dickinson, Jane Austen e as irmãs Charlotte e Emily Brontë. As autoras somente conseguiram um maior espaço no mundo das letras a partir do início do século 20, quando puderam investir em zonas

\footnotetext{
${ }^{1}$ DURAS. Escrever, p. 19.
} 
mais arriscadas, que não se restringiam a textos de cunho religioso, educativo, ou, ainda, que reforçassem papéis tradicionalmente considerados femininos. Desde o século que viu despontar as obras de Virginia Woolf, Marguerite Yourcenar, Doris Lessing, Clarice Lispector, Marguerite Duras e tantas outras, temos cada vez mais acesso a uma literatura escrita por mulheres, que é detentora de feições muito heterogêneas, na medida em que avança por dicções, temas e territórios diversos.

Expoente da produção artística francesa do século 20, Marguerite Duras (1914-1996) foi autora de novelas, peças de teatro e narrativas curtas, roteirista do aclamado filme Hiroshima, mon amour (1959), dirigido por Alain Resnais, e, ainda, diretora de seus próprios filmes, como India Song (1975). Inicialmente associada à corrente literária do Nouveau Roman e também ao projeto cinematográfico da nouvelle vague, Duras transitou por dois movimentos estritamente masculinos, em um período em que, cabe assinalar, não havia ainda ocorrido a luta pela liberação e os direitos da mulher. A produção literária da escritora transcende as discussões a respeito da ocorrência de uma literatura caracteristicamente feminina, uma vez que Duras se impôs como quem escreve com maestria sobre a fragilidade humana, as dificuldades que permeiam as relações, as escolhas subjetivas, a dor e a alegria inerentes à vida. A escritora não se furtou, entretanto, a explorar os mecanismos literários com o intuito de se aproximar de uma representação do feminino. Ao enfocarem temáticas existenciais, de modo bastante singular, as obras por ela criadas superaram certa resistência inicial do mercado editorial em relação à literatura feita por mulheres. E adquiriram a potência de textos clássicos, no sentido de que, com o transcurso do tempo, seguem comunicando distintos conteúdos a diferentes leitores.

Filha de professores emigrados, Duras nasceu na Indochina, no Sudeste Asiático, onde viveu até partir, aos 18 anos de idade, para a França. A infância atípica e as experiências da adolescência na colônia francesa marcariam de modo indelével o imaginário da escritora. Duras obteve seu grande êxito de público quando, aos 70 anos, escreveu $O$ amante (1984), contundente texto com fortes traços autobiográficos, pelo qual foi agraciada com o Prêmio Goncourt. A narrativa se desenvolve na Saigon dos anos 1920, no período entre-guerras, a partir do encontro que muda os rumos da vida de uma adolescente. Uma jovem branca de 15 anos atravessa o rio Mekong de balsa, destacando-se por usar um chapéu masculino, um vestido de seda roto e sapatos de lamé dourado para ir ao Liceu. Tudo transcorre como em um dia qualquer até o momento em que ela, subitamente, percebe-se observada por um homem em uma limusine negra. Os olhares se cruzam, ocorre o encontro e, logo, ela descobriria o amor e o sexo, ao tornar-se amante do rico e devotado chinês doze anos mais velho. 
A trajetória transgressora da jovem personagem, que se confunde imensamente com a história da própria Duras, representa uma afronta aos valores morais e costumes da época. A trama amorosa na qual a garota decide envolver-se representa o trespasse de um limite, a tomada de uma posição de ruptura em relação às normas sociais. O amante não é somente mais velho, é de naturalidade chinesa, condição que o caracteriza, aos olhos da sociedade da época, como inferior à menina branca, a despeito de que ele detenha muito mais posses do que ela. Viver sob suas próprias premissas é uma escolha que não permite retrocesso e que implica consequências diretas para menina. Sob tais circunstâncias de questionamento moral, com a amante do chinês, já não falavam mais as colegas do Liceu. Na colônia, devido à sua conduta, não poderia casar-se, assegurava-lhe a mãe. Decorre desse impasse a imagem de prostituta infantil que a jovem cria de si própria, porque mantém o relacionamento com o chinês. Quando o personagem feminino se coloca em desacordo com o papel social que é esperado que desempenhe, torna-se uma figura abjeta. Conforme assinala Ruth Silviano Brandão, ${ }^{2}$ a ruptura com o ideário de mulher implica em aversão:

Assim ela [a mulher] se configura como completude, face tranquilizadora de Narciso, ou, em contrapartida, a face que o questiona, enquanto desfusão, enquanto, ruptura da plenitude. É ideal a mulher que funciona como recusa da castração, que reassegura o narcisismo masculino, que é réplica da mãe, máxima figura fálica (...) É abjeta aquela que rompe com essa representação.

Diante das dificuldades financeiras, das turbulências familiares e da falta de perspectivas, impera, contudo, a necessidade de permitir-se buscar alguma forma de satisfação pessoal. A compensação financeira e a vivência da sexualidade motivam a garota a entregar-se ao jovem chinês rico. O envolvimento amoroso é, também, uma maneira de diferenciar-se da mãe, de traçar um caminho diverso, que não fosse aquele que ela lhe programara. Um modo de escapar ao destino de formar-se em licenciatura e tornar-se professora primária. Essa falta de identificação com a figura materna se demarca, de início, na confissão sobre a vergonha que sente diante da imagem desalinhada da matriarca, o que parece refletir-se na necessidade da jovem de vestir-se de uma maneira bastante particular, com o intuito de individualizar-se.

A construção dos personagens da obra de Duras rompe com a ideia convencionada de que fragilidade, delicadeza, indecisão e passividade são qualidades que estão diretamente relacionadas ao feminino. O texto durassiano contesta aquilo que somos socialmente determinados a encarar como uma condição de natureza da mulher, por meio da atuação dos personagens femininos e, em especial, da protagonista, jovem decidida e imbuída de

\footnotetext{
${ }^{2}$ BRANDÃO. Mulher ao pé da letra: a personagem feminina na literatura, p. 30.
} 
personalidade forte. Ao contrário do que se possa inicialmente supor, a garota inexperiente não age de modo vacilante. Ela governa a relação desde o primeiro contato com aquele que se tornaria o seu amante. Perturbada pelos credores e a vida difícil na colônia, a mãe, personagem anteriormente retratado com destaque no livro Uma barragem contra o Pacífico (1950), vive suas crises, aproxima-se da loucura, mas se mantém como o sustentáculo da perturbada família. No final da vida, consegue superar, inclusive, a ruína financeira, ao dirigir uma nova instituição educacional, o que lhe permite adquirir duas propriedades na França, que são dilapidadas mais tarde pelo irmão mais velho. Apática, ingênua e infantil, o personagem Hélène Lagonelle, colega de pensionato por quem a jovem se sente, de certo modo, atraída, é uma exceção entre os demais personagens femininos do texto. Como a jovem e a mãe, as demais mulheres evocadas como recordações no relato são figuras intensas e de espírito forte.

Detentores de menor representatividade na trama, os personagens masculinos se apresentam como extremos de comportamento. O irmão mais velho, descrito como "o reviraarmários”, “o assassino sem armas”, “deliquente”, conforma uma potência negativa na família. E constitui, desse modo, um contraponto à debilidade do irmão mais novo, sempre calado, oprimido e sem reação. O homem de Cholen, zeloso de seu amor pela menina branca, por sua vez, submete-se a todas as vontades da garota. Expõe-se a situações embaraçosas para tê-la a seu lado, mostra-se o parceiro mais vulnerável da relação, pois é aquele que sofre por amor. Entre a maldade e a ira do primogênito, a passividade do irmão mais novo e a cumplicidade e devoção do amante, o que sobrevém é o ímpeto da caçula, jovem que deseja se tornar escritora, e, que, para isso, sabe que deverá ser a primeira a partir.

O predomínio dos personagens femininos na narrativa se assinala com clareza em um dado trecho, quando a narradora, que rememora, observa: “A lembrança dos homens jamais se manifesta com a mesma luminosidade das recordações das mulheres.”3 Na tessitura da narrativa prevalece a visão dessa senhora, enquanto narradora-personagem, o que, no caso, projeta um olhar feminino sobre o relato. Estruturado como uma narrativa de cunho memorialístico, o texto é, preponderantemente, narrado em primeira pessoa, sob o ponto de vista da mulher que se recorda da adolescência. Ocorrem, contudo, algumas oscilações que, por vezes, dirigem o foco narrativo para a terceira pessoa do discurso. Dessa maneira, é estabelecido no texto um jogo de alternância entre os pronomes je/elle (eu/ela), em que o relato das lembranças migra, em certos trechos, do confessional e subjetivo que lhe

\footnotetext{
${ }^{3}$ DURAS. O amante, p. 56.
} 
caracteriza para um tom de impessoalidade e certo distanciamento. Isso acontece, por exemplo, quando a narração se refere a um sujeito denominado como "menina”, “jovem” ou “ela”. Esta ambiguidade constitutiva do texto de Duras, na análise de Mireille Calle-Gruber, ${ }^{4}$ representaria uma espécie de transformação do $e u$, sua conversão em ela, propiciada pelo papel desempenhado pelo personagem do amante. Ele seria o veículo, o meio, e também o espelho da mutação do eu, "e, de maneira mais complexa, do Eu que se vê transformar-se no Outro no olhar do Amante”. A relação perderia, portanto, o caráter dual de eu/ele, para conformar a tríade eu/ele/ela, em que o terceiro termo representaria alteridade.

Em A doença da morte (1982), livro que antecede $O$ amante, a desenvoltura do personagem feminino em relação ao masculino também é salientada. O texto não se vale da intensidade das relações familiares, baseadas em amor e aversão, proximidade e estranhamento, como ocorre no livro que lhe sucede. Nessa obra, Duras desenvolve, por meio de uma prosa poética apurada, uma narrativa de núcleo bem delimitado que, como em $O$ amante, reveste-se de uma forte carga de erotismo. O texto versa sobre o encontro de dois desconhecidos, que, pelo desejo de viver a experiência, confinam-se em um quarto de hotel por alguns dias. Nesse encontro, a impossibilidade de amar do homem - a doença da morte é posta à prova. A narrativa curta, acompanhada de notas que sugerem orientações sobre a possível encenação do texto, mais uma vez, apresenta o envolvimento erótico como tentativa de aplacar a solidão e a dificuldade existencial. O erotismo do relato está mais, propriamente, centrado na descrição da contemplação do corpo feminino e do prazer experimentado pela parceira. A mulher que permanece nua sobre a cama se expõe ao olhar do homem. E a interrogação a ser feita é sempre sobre o corpo da mulher, esse Outro. Ele, inquieto, estuda o corpo feminino como se dele pudesse extrair uma verdade essencial, uma réplica a seus anseios.

A estranha com quem divide o quarto é para esse homem um enigma, um mistério, como também o é para nós, leitores. Contribui diretamente para esse efeito de sentido a ambiguidade proporcionada pela utilização do pronome vous (você), empregado ao longo da narrativa em menção ao personagem masculino:

Você deveria não conhecê-la, tê-la encontrado em todos os lugares ao mesmo tempo, num hotel, numa rua, num trem, num bar, num livro, num filme, em você mesmo, em ti, no acaso do teu sexo erguido na noite que

\footnotetext{
${ }^{4}$ CALLE-GRUBER. Porquoi n’a-t-on plus peur de Marguerite Duras?, p. 116.
} 
clama por onde se pôr, por onde se desembaraçar dos choros que o impregnam. ${ }^{5}$

O narrador, espécie de diretor que orienta o desenrolar da dramatização, ao valer-se do pronome vous (você), em vez de referir-se ao homem por intermédio do pronome il (ele), parece, constantemente, invocar a nós, leitores, a tomar parte no relato. Com o emprego desse recurso narrativo, somos lançados à cena, convertidos em voyeurs, cúmplices do que se passa no quarto entre os desconhecidos que se tornam amantes. Somos postos na condição do amante doente, inábil com os sentimentos, que padece de solidão e busca respostas sobre sua condição, ao envolver-se com essa intrigante mulher. Entregue à experiência, ela é toda corpo sensível, cobiçoso de contato, tendente à realização do encontro. Ainda que impelida pelas vontades da carne, é a mulher quem, com parcimônia, busca responder às desejosas perguntas. Ela tenta dirimir as dúvidas do homem, que também se fazem nossas. É do interesse pela descoberta do feminino, de um contato com o íntimo da mulher, do reconhecimento do desejo e da repulsa capaz de ser suscitada por aquele corpo que lhe é diverso, de poder amá-lo, que advém a busca pelo encontro, pela conjunção ali perpetrada. Se a mulher que aceita viver com ele essa experiência limite percebe, aos poucos, a incapacidade de amar que o adoece, o homem tateia, observa e inquiri o que lhe parece muito mais insondável. O feminino é a grande intriga, o questionamento que lhe parece sem resposta:

Ela estaria sempre pronta, consentindo ou não. É neste ponto preciso que você nunca saberá nada. Ela é mais misteriosa que todas as evidências externas conhecidas até ali por você.

Você nunca saberá também, nem você nem ninguém, nunca, sobre como ela vê o mundo e você, o seu corpo e o seu espírito, e essa doença pela qual ela diz que você está tomado. (...) Porque você não sabe nada dela você diria que ela não sabe nada de você. Você permaneceria aí. ${ }^{6}$

A escritura de Duras, de acordo com Paulo Berned, ${ }^{7}$ aproxima-se de um

movimento que sugere a tradição dos contadores de histórias, permite-se que a palavra assuma seu papel ilimitado de criação de imagens (...) As imagens propostas por Duras iriam ao encontro do que ela chamou de narração psicológica; ou seja, realizam-se no íntimo de cada leitor.

Experimentada no exercício de diversas linguagens, Duras explora no texto as potencialidades expressivas da imagem como mecanismo de estabelecer sentidos. Com elas,

\footnotetext{
${ }^{5}$ DURAS, A doença da morte, p. 7.

${ }^{6}$ DURAS. A doença da morte, p. 19-21.

${ }^{7}$ BERNED. A escrita de transgressão e denúncia na obra de Marguerite Duras, p. 4.
} 
parece delinear cenários para uma encenação, imprimir fotogramas dos personagens no texto, projetando, desse modo, estímulos a serem moldados pela elaboração do leitor. Em A doença da morte, a temporalidade também parece concorrer para que o texto alcance tal efeito de sentido. O transcurso do tempo se destila juntamente com as impressões desse você e dessa ela que se põem em interação, vestígios que se sucedem uns aos outros, em um presente fugidio. As interrogações e lampejos se acumulam com os instantes que se somam, à medida que o tempo acertado para o experimento de convivência se esgota. Esse tempo de apreensão da experiência vivido pelos personagens, que se pontua pelas especulações e constatações desferidas, contribui para que o leitor mergulhe nessa narração psicológica que lhe é proposta.

A mulher que partilha o quarto com o estranho afirma ter aceitado fazê-lo ao constatar a espécie de “morte em vida” de que ele estava acometido por não amar. Ela vive o encontro com intensidade, pelo prazer sexual que lhe proporciona, pois compreende que a relação não prosseguirá para além do que foi acertado inicialmente. Findado o prazo, ela parte sem despedir-se, deixando o homem atordoado perante sua ausência. Nesse sentido, é preciso observar que rompida a vertigem do desejo, a separação de corpos faz, imediatamente, emergir a clareza de sentimentos, o dar-se conta de haver se envolvido emocionalmente. $\mathrm{Na}$ ausência daquela que ainda lhe é desconhecida, o desorientado amante percebe a perda do que, finalmente, seria um possível amor. De maneira semelhante, em $O$ amante, quando a jovem parte para a França, para perseguir seu sonho de ser escritora e porque sua situação se tornou insustentável, já embarcada no vapor, tem, de repente, também sua epifania. Ela se descontrola e chora, ao perceber que não estava tão certa de não haver amado o chinês, pois considera que poderia ter tido uma leitura errônea de seus próprios sentimentos. Entretanto, em ambas as narrativas, o reconhecimento é tardio, ocorre quando o objeto de afeição foi, em absoluto, perdido. Não há retorno, apenas uma espécie de sentimento de disjunção, uma angústia pela desconfiança de ter vivido algo maior e, no entanto, já tê-lo perdido.

Esta zona nebulosa e fugidia que parece caracterizar o feminino, em que se empenha o amante de A doença da morte e que a ele parece inalcançável, constitui o substrato que Duras busca tornar passível de ser expresso em palavras. Ela assume o desafio de transpor, por meio da matéria textual, o que parece ser da ordem do inapreensível. E para isso, tem de jogar com a linguagem, suspender regras, levar a escritura a um limite de criação. A escritora demonstra habilidade expressiva ao assumir o risco de fundar uma linguagem e um estilo, caminho em que poderia ser fácil perder-se, no desejo de conseguir aproximar-se do feminino, do erotismo, do conflito existencial e do amor. Duras entende que para alcançar comunicar conteúdos como esses é preciso manipular a língua, reordenar a sintaxe, deslocando palavras, 
valer-se de reiterações, para tornar a "escritura fluida”, capaz de exprimir de modo rápido e preciso, o que muitas vezes é rarefeito, pouco tangível. Nas palavras de Duras: ${ }^{8}$

A escritura fluida é uma escritura distraída, diria eu, uma escritura que corre, que quer apanhar as coisas mais do que dizê-las. A crista das palavras. A escritura progride sobre a crista, para ir depressa, não perder nada, que é o drama quando se escreve.

O texto, de uma intensidade emocional rara, utiliza-se de uma linguagem ajustada, que torna a leitura corrente e captura o leitor por meio de uma espécie de magnetismo. O destaque concedido aos personagens femininos e o modo pelo qual são construídos, a estrutura narrativa, bem como os recursos formais empregados nos textos analisados de Duras nos dirigem a uma busca por significar o feminino a partir das possibilidades dessa escritura transgressora. Para Duras, ${ }^{9}$ a experiência de escrever e ler os seus textos é dolorosa, justamente porque nos conduz a "um terreno de experimentação"; “é um trabalho relativo a uma região (...) ainda não explorada, talvez (...) esse feminino, digamos”. Nesse sentido, o que se apreende da produção de Duras é que para experimentar essa "região”, é preciso jogar com as possibilidades expressivas da linguagem, mobilizar a escritura, e fazer da literatura, igualmente, um meio de experimentação, em que é possível viver o risco da invenção. É nesse lugar limítrofe, nessa “crista da linguagem”, que a escritora nos permite vislumbrar figurações do feminino em sua escritura, ao fundar um “texto de gozo”, que agencia o leitor, ao fazer os sentidos ecoarem pelas manobras linguageiras. O feminino ressoa nesse espaço de experimentação da escritura, que dá voz do texto a representações que nos acercam, fazemnos avançar sobre o que parece ser da ordem do indizível.

\begin{abstract}
In this analysis of The Malady of Death (1982) and The Lover (1984), Marguerite Duras's writing plays with the possibilities of representation of the feminine through the construction of characters, the narrative structure, as well as the formal language resources employed.
\end{abstract}

\footnotetext{
${ }^{8}$ DURAS. Entrevista televisiva concedida a Bernard Pivot, na ocasião do lançamento do livro $O$ amante.

${ }^{9}$ DURAS. Boas Falas: conversas sem compromisso, p. 16.
} 


\section{KEYWORDS}

Writing, feminine, erotism, French Literature

\section{REFERÊNCIAS}

BERNED, Pablo Lemos. A escrita de transgressão e denúncia na obra de Marguerite Duras. In: ANAIS DO XII CONGRESSO INTERNACIONAL DA ABRALIC. Tessituras, Interações, Convergências. São Paulo: USP, 2008.

BRANDÃO, Ruth Silviano. Mulher ao pé da letra: a personagem feminina na literatura. 2 ed. Belo Horizonte: Editora UFMG, 2006.

CALLE-GRUBER, Mireille. Porquoi n'a-t-on plus peur de Marguerite Duras?. Littérature, Paris, v. 63, p.104-119, out. 1986.

DURAS, Marguerite. A doença da morte. Trad. Jorge Bastos. Rio de Janeiro: Taurus, 1984. Ed. Bilíngue.

DURAS, Marguerite. Entrevista televisiva concedida a Bernard Pivot, na ocasião do lançamento do livro O amante. Programa Apostrophes. Antenne 2, 1984.

DURAS, Marguerite. Escrever. Trad. Rubens Figueiredo. Rio de Janeiro: Rocco, 1994.

DURAS, Marguerite. O amante. Trad. Aulyde Soares Rodrigues. Rio de Janeiro: O Globo; São Paulo: Folha de S.Paulo, 2003.

DURAS, Marguerite; GAUTHIER, Xaviére. Boas falas: conversas sem compromisso. Trad. de Sieni Maria Campos. Rio de Janeiro: Record, 1974. 